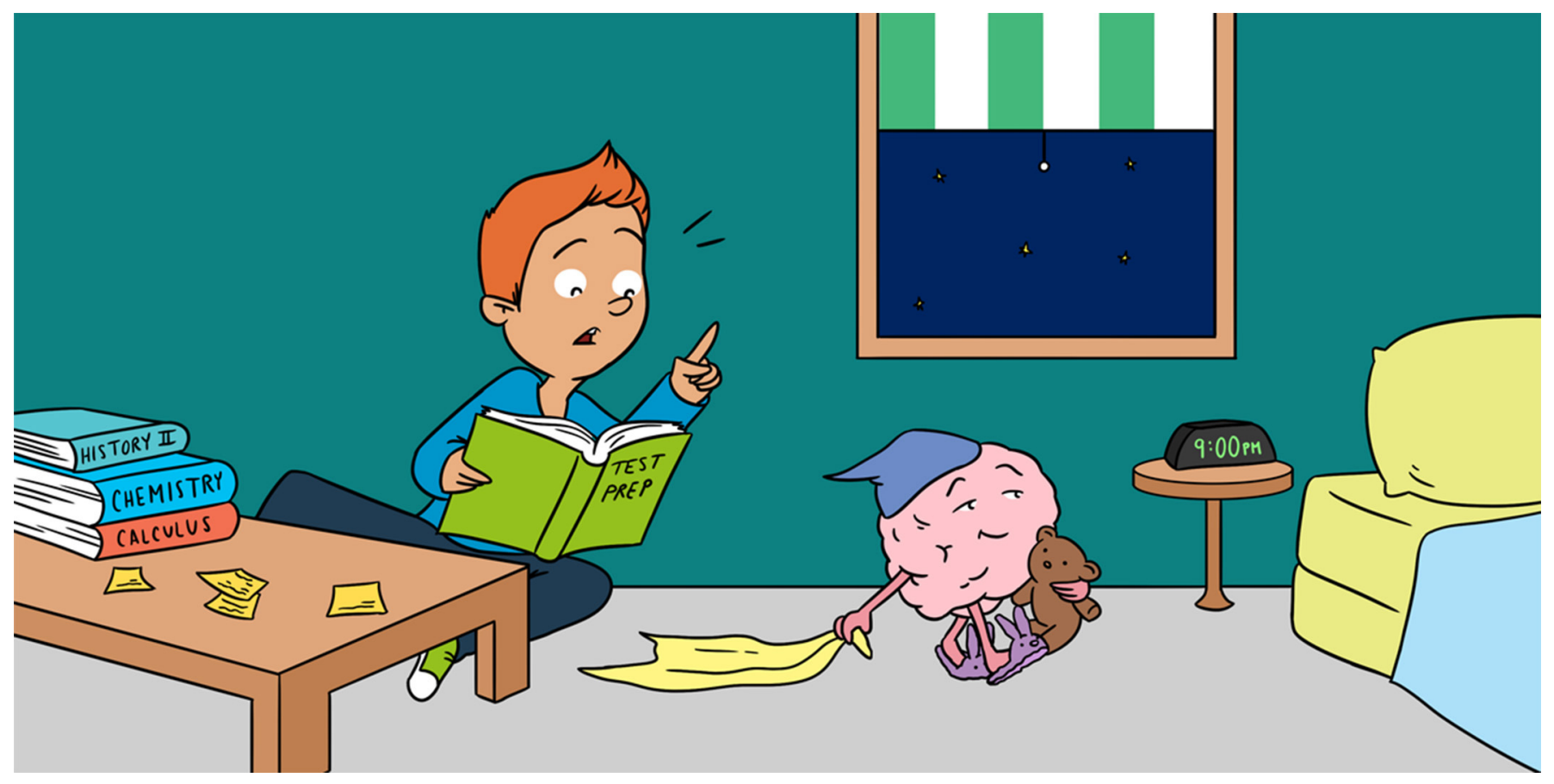

\title{
FROM ZZZs TO AAAs: WHY SLEEP IS AN IMPORTANT PART OF YOUR STUDY SCHEDULE
}

\section{Emma James $^{1 *}$, Ann-Kathrin Joechner ${ }^{2 *}$ and Beate E. Muehlroth ${ }^{2 *}$}

${ }^{1}$ Department of Psychology, University of York, York, United Kingdom

${ }^{2}$ Center for Lifespan Psychology, Max Planck Institute for Human Development, Berlin, Germany

\section{YOUNG REVIEWERS:} HATHAWAY BROWN SCHOOL AGES: $14-15$

THE SCHOOL FOR

SCIENCE AND MATH AT VANDERBILT AGES: $14-15$
All of us sleep. While adults spend about one-third of their time asleep, the younger you are, the more you sleep. However, this does not mean that children and teenagers are being lazy by spending too much time in bed. In fact, not getting enough sleep usually makes people feel tired, less effective, and unable to concentrate. Not only should you avoid these consequences of bad sleep, but you should also prioritize good sleep. Good sleep restores your body and brain, and offers an opportunity for your brain to reorganize itself after a busy day. In this article, we consider why sleep is especially important for supporting memory. Your ability to learn, remember, and refine your brain is extraordinary during childhood and adolescence, so sleep is particularly important during these stages. We explain the links between brain and sleep changes as you grow older, and why sleep should be an important part of your study schedule.

As you get nearer and nearer to a test at school, sometimes it feels like there is so much to learn in so little time. So why waste time in 
Figure 1

How we measure sleep. (Left) We measure the activity of neurons, eyes, and muscles using little sensors. (Right) The activity is displayed on a computer screen as wiggly lines. During light non-REM sleep (pink area) we detect sleep spindles in the brain activity. During deeper non-REM sleep-otherwise known as slow-wave sleep-chin muscles relax (the line gets flatter) and the curves representing brain activity get really slow and big (slow waves). During REM sleep (blue area) the muscle activity is the lowest, brain activity gets faster, and the eyes start making rapid zigzag movements.

\section{NEURONS}

Tiny nerve cells in the brain that store and transfer signals and information.

\section{RAPID EYE}

MOVEMENT (REM) SLEEP

Sleep stage in which the eyes move quickly and the muscles are extremely relaxed, often associated with vivid dreams.

\section{SLEEP SPINDLES}

Short periods of increased activity in the brain that we believe help with efficient communication between different parts of the brain.

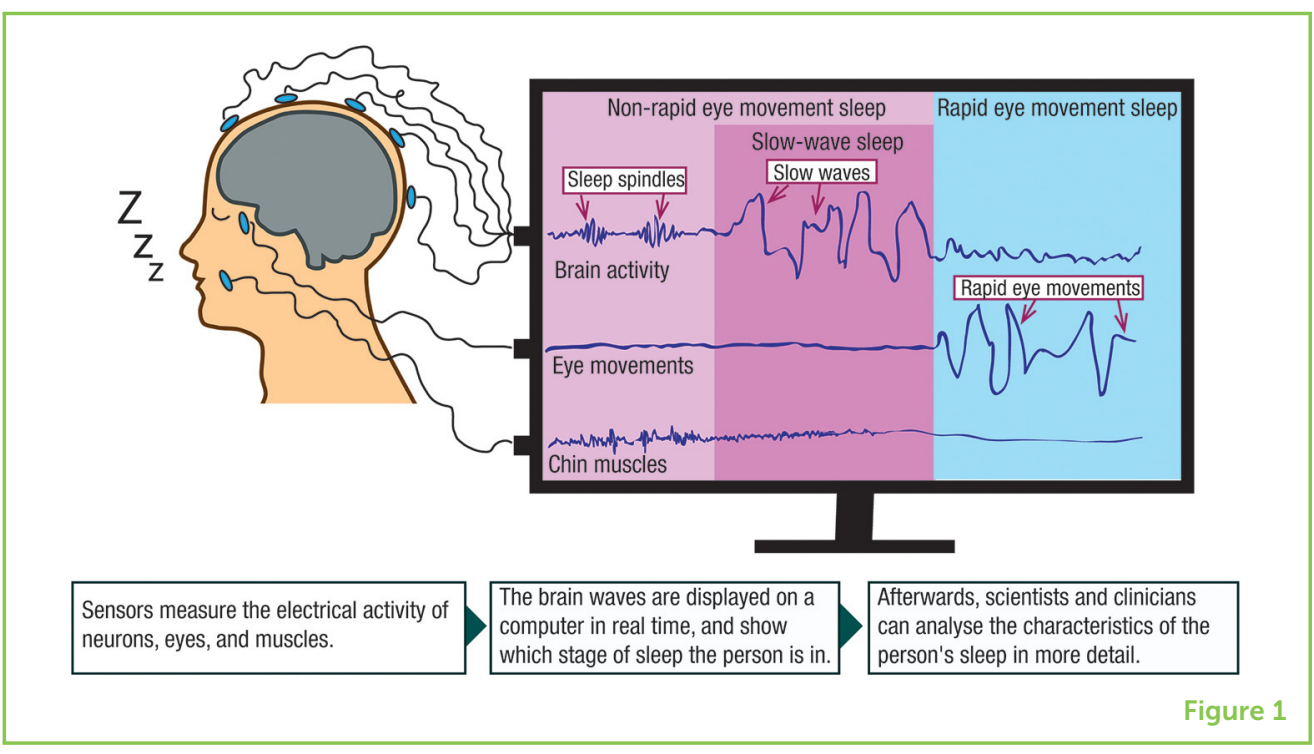

bed when you could use that time to study? Staying up late to cram in some extra learning time might seem a tempting thought, but sleep is vital for your body and brain. It keeps you healthy and restores your energy so you feel alert and active the next day. Sleep also provides a time for the brain to remodel and refine its structure and function to your individual needs and experiences. The sleeping brain is not only important for general brain development but-fortunately-also does some pretty important work on your memories. Scientists have shown that the brain's activities during sleep help to save new knowledge to memory as well as prepare for new learning the next day. This means that spending time asleep is much better than trying to pull an "all-nighter" in the run-up to exams. While this is important throughout life, the ability to reshape your brain and your capacity to learn is extraordinary across childhood and adolescence, and so is your sleep across this period.

\section{THE SLEEPING BRAIN}

The sleeping brain is not always doing the same thing. A good night's sleep cycles through different sleep stages, determined by muscle and eye movements, and the activity of tiny nerve cells in the brain (called neurons). Scientists can measure this activity by placing small sensors beside a person's eyes, on the chin, and on the head while the person sleeps (see Figure 1). Sometimes the neurons act very quickly and chaotically, similar to when the brain is awake and busy. This is the case during rapid eye movement sleep (REM), a sleep stage during which the eyes are moving very quickly, muscles are extremely relaxed, and the brain is engaging in very vivid dreams. The remaining sleep stages are referred to together as non-rapid eye movement sleep (non-REM). During light non-REM sleep, we see short bursts of brain activity called sleep spindles (see Figure 1). During deep non-REM sleep, neurons in the brain show slow rhythmic activity similar to gigantic waves in the 
Figure 2

How sleep changes across the lifespan. The older people get, the less time they spend asleep. Moreover, the balance between REM and non-REM sleep changes during childhood, and as children get older, less time is spent in deep non-REM sleep, so-called slow-wave sleep (Adapted from Roffwarg et al. [1]. Reprinted with permission from AAAS)

\section{SLOW-WAVE SLEEP}

The deepest phase of non-REM sleep, during which the neurons in the brain show slow rhythmic activity (slow waves), thought to be important for the storage of lasting memories.

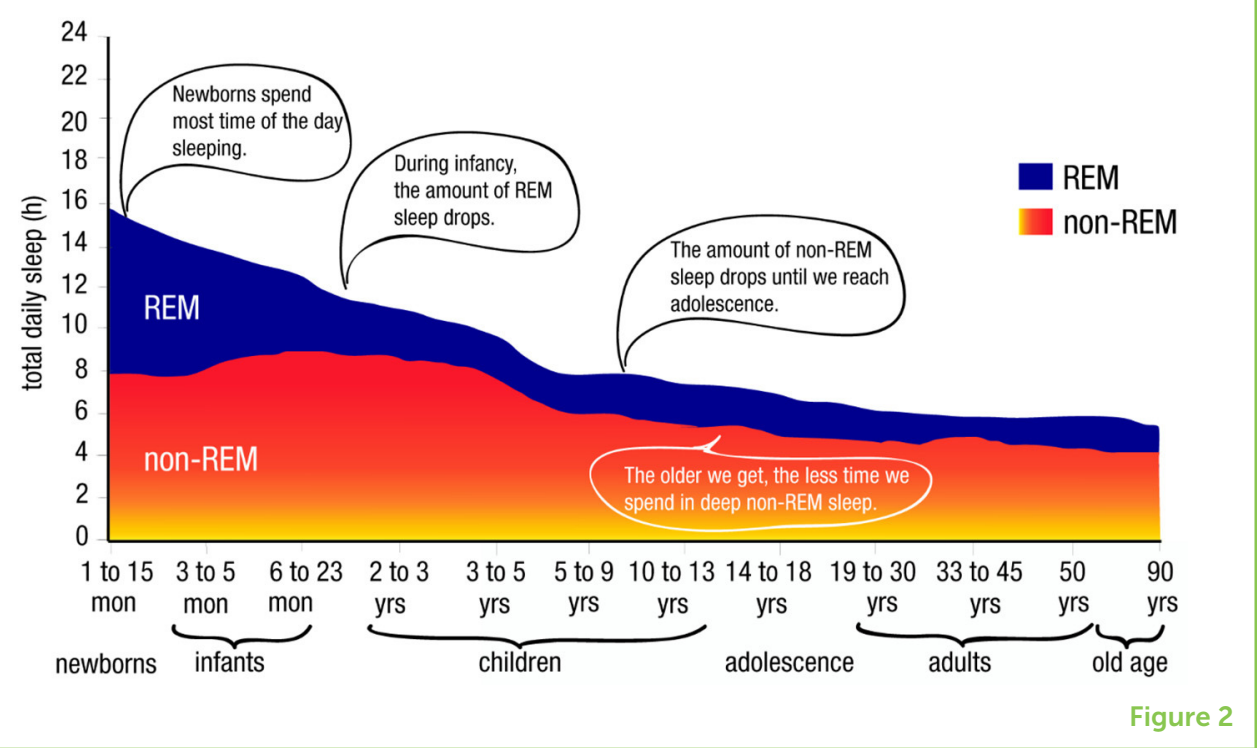

ocean (Figure 1), called slow waves. Because of this, deep non-REM sleep is often referred to as slow-wave sleep. Both sleep spindles and slow waves are specialists in remodeling the brain, meaning that the more they are present, the more the brain is being shaped.

\section{THE BRAIN UNDER RECONSTRUCTION}

As a newborn, you spent more time asleep than awake. But the older you get, the less you sleep. It is not just the amount of sleep that changes during development but, importantly, the balance between different sleep stages also changes. Generally, as you grow older, you get less and less slow-wave sleep, while the proportion of light non-REM sleep increases (Figure 2). Scientists believe that these changes in sleep may tell us about the brain's potential to reconstruct itself.

From infancy to adolescence, your brain undergoes major reorganization and optimization to deal with your daily needs and experiences. New connections between brain cells are built, connections you do not need are removed, and the communication of information along important neuron tracks speeds up. Crucially, when a specific part of the brain is under reconstruction, the neurons in that region show more slow rhythmic activity during slow-wave sleep. For example, scientists in Switzerland recorded the sleep of 40 children and young adults, and also measured their performance on certain tasks [2]. Interestingly, they found that sleep slow waves were most powerful in the brain region responsible for the skills participants were learning at each age, and the slow waves in those brain regions got weaker once the skill was better developed. For instance, in late childhood when children get really good at performing complex movements, like riding a bike-maybe even hands-free-slow waves 


\section{NEOCORTEX}

The outer layers of the brain that are thought to store knowledge for the longer term. were most powerful in the brain region responsible for performing movements. The scientists also saw this optimization in the brain's structure when the participants went in the brain scanner: the brain's outer layer, the neocortex, was thinner in these regions, reflecting "fine-tuning" of the brain to perform tasks more efficiently. These relationships between slow waves, skills, and brain structure lead researchers to think that looking at slow rhythms during sleep might help us to learn how the brain is developing.

Unlike slow waves, which decline as the brain matures, the sleep spindles that characterize light non-REM sleep get more numerous and faster throughout childhood and adolescence. Some scientists think that the speeding up of sleep spindles during childhood and adolescence reflects faster and more efficient communication between different parts of the brain. In one of our studies, we found that children who showed the biggest increases in the number of spindles over a seven-year period performed better on tests of general mental ability at ages 14-18 [3]. Unfortunately, we do not yet know exactly how spindles are helping brain development, and this is an exciting area that scientists are still trying to understand.

\section{SLOW AND STEADY WINS THE RACE}

By looking at sleep, we can understand how the brain changes as children grow older and learn new skills, like riding a bike. However, sleep performs another important task. It helps you to form long-lasting memories of new facts, like information you learn at school.

Lots of experiments have shown that sleep can help you to remember the new things that you learn. Some studies have even shown that memories can get better with sleep, without any extra studying! For example, researchers at the University of York taught 7- to 12-year-old children new words in either the morning or the evening [4]. When the researchers tested the memory of the children 12 hours later, those who had learned in the evening and then gone to sleep could remember more words than the children who stayed awake all day. In fact, they could recall more of the words than they could before they went to bed. How can that be?

Scientists believe that the brain has two different learning systems, a fast one and a slow one. These two learning systems can be thought of like the slow tortoise and the speedy hare in the old fable. In the tale, the hare speeds off very rapidly in his race against the tortoise. Pleased with his progress and confident of winning, he takes a nap midway that allows the slow and steady tortoise to overtake and win the race. One learning system in the brain works like the speedy hare: it helps you to learn new information very quickly during the day and gives the information a head start in memory. However, the 
Figure 3

How slow-wave sleep helps with memory storage. The hippocampus (brown), a small structure deep in the brain, is the fast learning system that helps to quickly acquire new knowledge. To make sure that these new memories are safely stored in the brain, the hippocampus communicates them to the slow-learning neocortex, the outer layers of the brain (green), during sleep. By acting out a sequence of slow waves (green line), sleep spindles (pink line), and fast waves (brown line) the two regions talk to each other, allowing new information to become strengthened and linked to older knowledge already present.

\section{HIPPOCAMPUS}

A brain structure deep inside the brain that helps to support fast learning of new information.

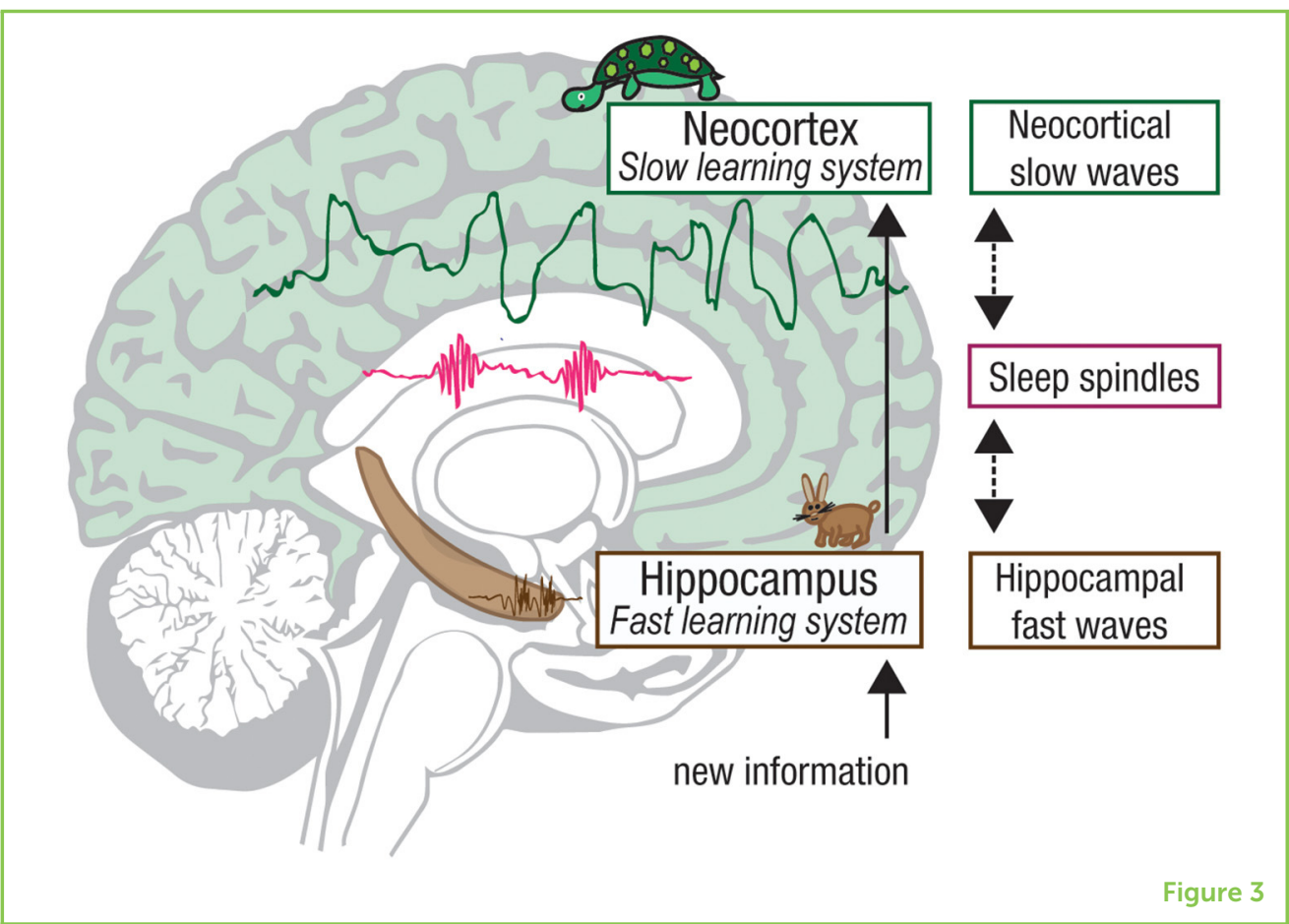

second learning system is much slower and wiser, like the tortoise, and carefully links the new information to things that we already know. This slower learning system wins out in the long-term, helping you to remember new information in the future. Much like in the tale, the "tortoise" memory system can take over when you give your brain an opportunity to sleep.

Studies show that a region deep in the brain (the hippocampus) gets the head start in learning like the speedy hare, while the outer layers of the brain (the neocortex) act like the slow tortoise (see Figure 3). During slow-wave sleep, the speedy hippocampus repeats the information it has learned during the day and communicates it to the slow-learning neocortex. Many scientists think that the brain is acting out a very specific sequence of slow waves, sleep spindles, and very fast waves in the hippocampus, which allow the two learning systems to talk to each other. This communication strengthens fragile memories for the longer term and links them with older knowledge already stored in the neocortex [5]. Scientists in Belgium showed that this memory-strengthening process can happen even during a nap [6]. They taught children aged 8-12 some "magical" meanings for made-up objects (for example, one object could see through doors, another object could stop the rain), and then tested their memory for these associations while measuring brain activity. Immediately after learning, the hippocampus responded to the learned meanings. Half the children then took a 90-min nap, whereas the other half stayed awake. In a second memory test, only children who had slept showed greater brain activity in the neocortex when remembering the 
meanings. So, even after a short nap, the slow tortoise system can win the memory race.

\section{SO SLEEP TIGHT, WAKE UP BRIGHT!}

Now you know that sleeping definitely is not a waste of time. Rather, sleep allows your memories to become as good and long-lasting as possible. Sleep is essential for allowing your brain to reorganize as you grow up and experience the world, and for helping you to remember all the new things that you learn. In the long run, children who get more sleep perform better at school, and even do better in exams than children who stay awake late to do extra studying [7]. So, be sure to make sleep an important part of your study schedule, and let your brain do the hard work while you relax for the night.

\section{ACKNOWLEDGEMENTS}

We would like to wholeheartedly thank those who assisted in the translation of the articles in this Collection to make them more accessible to kids outside English-speaking countries, and for the Jacobs Foundation for providing the funds necessary to translate the articles. For this article, we would especially like to thank Nikki Lee for the Dutch translation. EJ was supported by ESRC Fellowship ES/T007524/1. BM and A-KJ were supported by the project "Lifespan Rhythms of Memory and Cognition (RHYME)" at the Center for Lifespan Psychology, Max Planck Institute for Human Development, Berlin, Germany. A-KJ is a fellow of the International Max Planck Research School on the Life Course (LIFE; https://www.imprs-life.mpg.de/en).

\section{REFERENCES}

1. Roffwarg, H. P., Muzio J. N., and Dement W. C. 1966. Ontogenetic development of the human sleep-dream cycle. Science 152:608.

2. Kurth, S., Ringli, M., LeBourgeois, M. K., Geiger, A., Buchmann, A., Jenni, O. G., et al. 2012. Mapping the electrophysiological marker of sleep depth reveals skill maturation in children and adolescents. Neuroimage 63:959-65. doi: 10.1016/j.neuroimage.2012.03.053

3. Hahn, M., Joechner, A.-K., Roell, J., Schabus, M., Heib, D. P., Gruber, G., et al. 2019. Developmental changes of sleep spindles and their impact on sleep-dependent memory consolidation and general cognitive abilities: a longitudinal approach. Dev. Sci. 22:e12706. doi: 10.1111/desc.12706

4. Henderson, L. M., Weighall, A. R., Brown, H., and Gaskell, M. G. 2012. Consolidation of vocabulary is associated with sleep in children. Dev. Sci. 15:674-87. doi: 10.1111/j.1467-7687.2012.01172.x 
5. Wilhelm, I., Prehn-Kristensen, A., and Born, J. 2012. Sleep-dependent memory consolidation-what can be learnt from children? Neurosci. Biobehav. Rev. 36:1718-28. doi: 10.1016/j.neubiorev.2012.03.002

6. Urbain, C., De Tiège, X., De Beeck, M. O., Bourguignon, M., Wens, V., Verheulpen, D., et al. 2016. Sleep in children triggers rapid reorganization of memory-related brain processes. Neuroimage 134:213-22. doi: 10.1016/j.neuroimage.2016.03.055

7. Gillen-O'Neel, C., Huynh, V. W., and Fuligni, A. J. 2013. To study or to sleep? The academic costs of extra studying at the expense of sleep. Child Dev. 84:133-42. doi: $10.1111 / j .1467-8624.2012 .01834 . x$

SUBMITTED: 30 September 2019; ACCEPTED: 26 March 2020; PUBLISHED ONLINE: 29 April 2020.

EDITED BY: Nienke Van Atteveldt, Vrije Universiteit Amsterdam, Netherlands

CITATION: James E, Joechner A-K and Muehlroth BE (2020) From ZZZs to AAAs: Why Sleep Is an Important Part of Your Study Schedule. Front. Young Minds 8:51. doi: 10.3389/frym.2020.00051

CONFLICT OF INTEREST: The authors declare that the research was conducted in the absence of any commercial or financial relationships that could be construed as a potential conflict of interest.

COPYRIGHT (c) 2020 James, Joechner and Muehlroth. This is an open-access article distributed under the terms of the Creative Commons Attribution License (CC BY). The use, distribution or reproduction in other forums is permitted, provided the original author(s) and the copyright owner(s) are credited and that the original publication in this journal is cited, in accordance with accepted academic practice. No use, distribution or reproduction is permitted which does not comply with these terms.

\section{YOUNG REVIEWERS}

\section{HATHAWAY BROWN SCHOOL, AGES: 14-15}

We are students from the Science Research \& Engineering Program at Hathaway Brown School. We enjoy learning about the peer review process, learning how to communicate science to different audiences, and offering our suggestions. We are helped by our Science Mentor, Crystal Miller.

\section{THE SCHOOL FOR SCIENCE AND MATH AT VANDERBILT, AGES: 14-15}

We are a class of students from all over Nashville, who come together once per week at Vanderbilt to learn more about science, technology, engineering, and mathematics. We conduct experiments in our classroom and in labs on campus! 


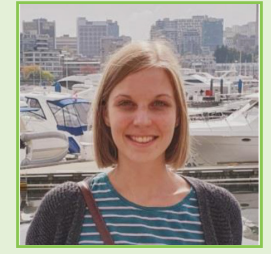

\section{AUTHORS}

\section{EMMA JAMES}

In the run-up to school exams, I would insist to my parents that I had not learned enough to go to bed early. I hate to admit it, but my research has taught me my parents were right: I am amazed at what sleep does for memory. I am particularly interested in how sleep helps us to learn new words, and why some children find this learning more difficult than others. I work at the University of York (UK), but have also lived in Bristol, Oxford, Lancaster, London, and in America. In my spare time, I like running, cooking, and playing the piano. *emma.james@york.ac.uk

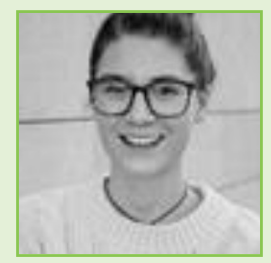

\section{ANN-KATHRIN JOECHNER}

I love sleep-not only because I personally like to sleep, but because I think it is amazing how active the brain is during a time where we seem inactive and have no conscious experience. Since I was a student at university, I have been fascinated by how sleep helps the brain to restructure and thus to retain new memories, and I have tried to understand it ever since. As childhood is a time of massive brain and cognitive changes, I am especially interested in how sleep supports memory across childhood and how the development of the brain is related to this. *joechner@mpib-berlin.mpg.de

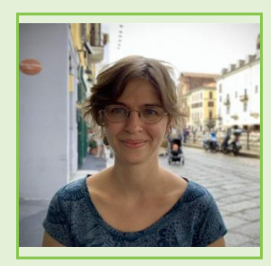

\section{BEATE E. MUEHLROTH}

When I was 6 years old, I could beat my parents when we were playing the matching pairs game. Of course, at that time I did not know how special a child's brain is. In my research, I want to find out what the brain is doing when we are learning and remembering and how sleep supports these tasks. Most of the time, I am trying to understand if bad sleep, as we might observe in our grandparents, could explain why older people forget more of the things they learned throughout the day. *beatemuehlroth@gmail.com 